\title{
Direct anterior versus posterolateral approaches for clinical outcomes after total hip arthroplasty: a systematic review and meta-analysis
}

Wang Chen, Jian-Ning Sun, Ye Zhang, Yu Zhang, Xiang-Yang Chen ${ }^{*}$ (D) and Shuo Feng ${ }^{*}$

\begin{abstract}
Objective: The main objective of our study was to compare the intraoperative and postoperative outcomes of direct anterior approach (DAA) with posterolateral approaches (PLA).

Methods: We searched Cochrane library, Web of Science, and PubMed for literatures comparing DAA with PLA. On the basis of inclusion and exclusion criteria, relevant literatures were selected. Two members independently screened qualified literatures, evaluated the literature quality, and extracted data information.

Results: Eighteen randomized controlled trials (RCTs) and non-RCTs totaling 34,873 patients (DAA = 9636, PLA = 25237) were contained in this systematic review and meta-analysis. The results showed that DAA were reduced in terms of length of hospital stay (weighted mean difference $(\mathrm{WMD})=-0.43,95 \%$ confidence interval $(\mathrm{Cl})-0.78$ to $-0.09, P=0.01$ ), LLD (WMD $=-2.00,95 \% \mathrm{Cl}-2.75$ to $-1.25, P<0.00001$ ), PE/DVT (WMD $=0.36,95 \% \mathrm{Cl} 0.15$ to 0.85 , $P=0.02$ ), dislocation (WMD $=0.42,95 \% \mathrm{Cl} 0.30$ to $0.59, P<0.00001$ ) and visual analog scale (VAS) (WMD $=-0.57$, $95 \% \mathrm{Cl}-0.91$ to $-0.23, P=0.0009)$ compared with PLA; however, DAA compared with the PLA was increasing in terms of operative time ( $\mathrm{WMD}=14.81,95 \% \mathrm{Cl} 7.18$ to 22.44, $P=0.0001)$, intraoperative blood loss (WMD $=105.13$, $95 \% \mathrm{Cl} 25.35$ to $184.90, P=0.01)$, fracture $(\mathrm{WMD}=1.46,95 \% \mathrm{Cl} 1.00$ to $2.11, P=0.05)$, and Harris hip score (HHS) $(\mathrm{WMD}=1.19,95 \% \mathrm{Cl} 0.77$ to $1.61, P<0.00001)$.
\end{abstract}

Conclusions: DAA was preferable effectiveness to PLA in early pain relief and functional recovery; however, PLA has a shorter operation time, intraoperative less blood loss and fracture.

Trial registration: Registration ID, CRD42020151208

Keywords: Total hip arthroplasty, Direct anterior approach, Posterolateral approach

\section{Introduction}

Total hip arthroplasty (THA) is a valid method for the treatment of hip diseases such as femoral neck fracture, aseptic necrosis of femoral head, developmental hip dysplasia, and rheumatoid arthritis [1]. It can significantly eliminate the patients' hip pain, restore hip function, get

\footnotetext{
*Correspondence: xzchenxiangyang@163.com; xzf50561@163.com Department of Orthopedic Surgery, Affiliated Hospital of Xuzhou Medical University, 99 Huaihai Road, Xuzhou 221002, Jiangsu, China
}

rid of pain, and improve the quality of life [2]. During the 10-year follow-up, the clinical efficacy of THA has been significantly improved and the survival rate of the prosthesis exceeded 95\% [3].

There are various approaches for THA: anterolateral approach (ALA), posterolateral approaches (PLA), direct anterior approach (DAA), direct lateral approach (DLA), etc. ALA is performed via the gluteus medius, vastus lateralis, and external rotators [4]. Static Trendelenburg

(c) The Author(s). 2020 Open Access This article is licensed under a Creative Commons Attribution 4.0 International License, which permits use, sharing, adaptation, distribution and reproduction in any medium or format, as long as you give appropriate credit to the original author(s) and the source, provide a link to the Creative Commons licence, and indicate if changes were made. The images or other third party material in this article are included in the article's Creative Commons licence, unless indicated otherwise in a credit line to the material. If material is not included in the article's Creative Commons licence and your intended use is not permitted by statutory regulation or exceeds the permitted use, you will need to obtain permission directly from the copyright holder. To view a copy of this licence, visit http://creativecommons.org/licenses/by/4.0/ The Creative Commons Public Domain Dedication waiver (http://creativecommons.org/publicdomain/zero/1.0/) applies to the data made available in this article, unless otherwise stated in a credit line to the data. 


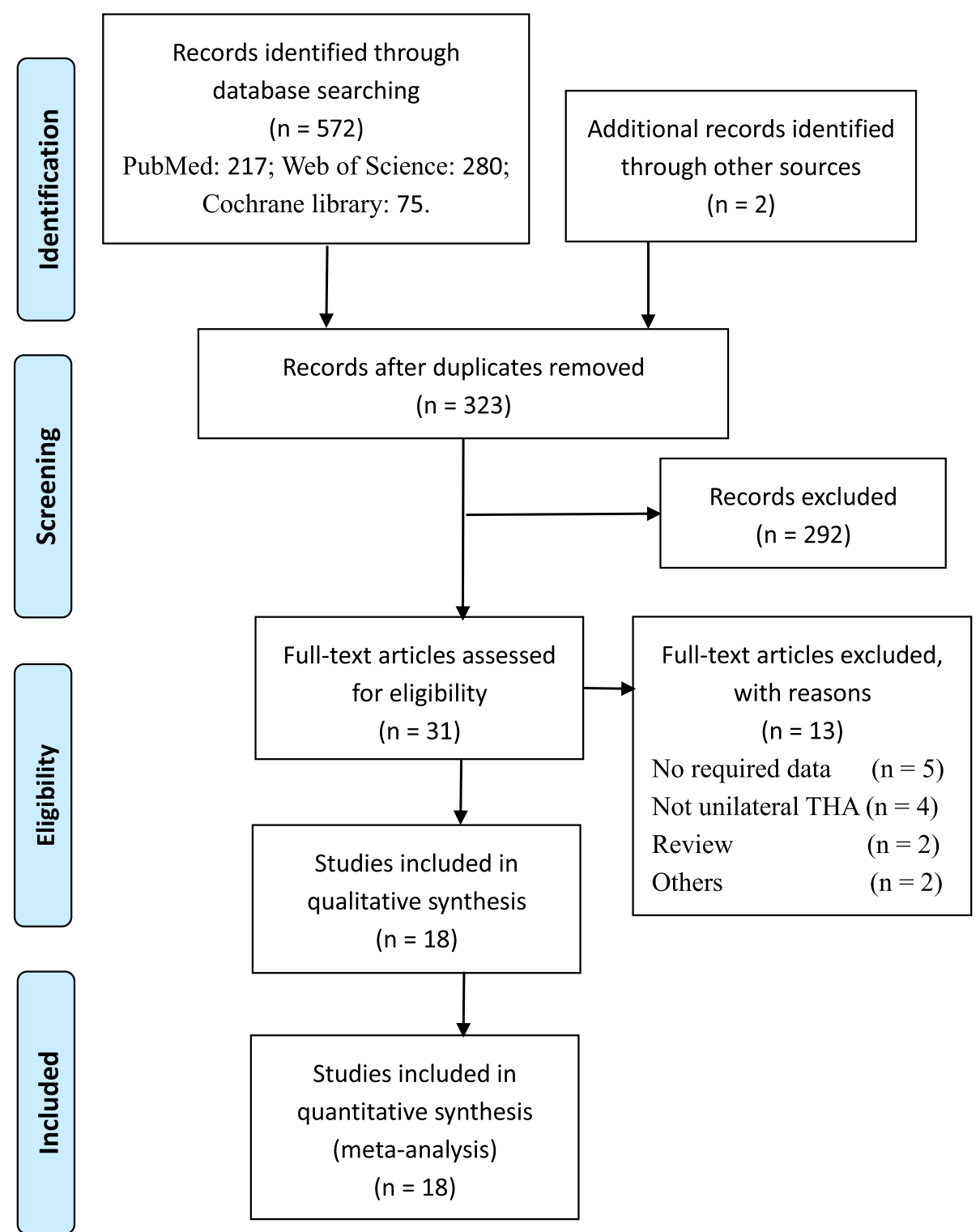

Fig. 1 The flow diagram of literature selection

test showed positive evidence, suggesting that ALA increases hip load and affected hip abduction. Posterior approach is the most widely applied total hip arthroplasty in the world [5]. The direct anterior approach does not cut off any muscle tissue around the hip, it does not cause any damage to the posterior joint capsule particularly, theoretically reducing the risk of dislocation $[6,7]$. Registration data from the UK and New Zealand indicate that most primary THA operations are performed using PLA, and less than $5 \%$ of surgeons use DAA $[8,9]$. Some scholars reported that patients who received PLA had higher postoperative levels of creatine kinase, a marker of muscle inflammation [10].
Alternative, less invasive approaches to total hip arthroplasty are attracting increasing attention [11]. Studies have shown that MIS-THA (little or no muscle dissection) can reduce soft tissue injury and blood loss, further promote postoperative recovery and accelerate the recovery of normal daily functions [12-14]. Surgeons can improve the DAA based on the gap between tensor fascia lata, sartorius, and rectus femoris muscle (Heuter gap) [15]. Relative to the conventional PLA, the method of DAA has the benefits of less bleeding, shorter duration of pain, shorter length of hospital stay, and a lower rate of hip dislocation. On the contrary, many of the literatures have made clear that two types of THA have similar prognosis in the early postoperative period; however, the incidence of 
Table 1 General characteristic of the included studies

\begin{tabular}{|c|c|c|c|c|c|c|c|c|}
\hline \multirow[t]{2}{*}{ Author/year } & \multirow[t]{2}{*}{ Country } & \multicolumn{4}{|l|}{ DAA/PLA } & \multirow[t]{2}{*}{ Study } & \multirow{2}{*}{$\begin{array}{l}\text { Follow- } \\
\text { up }\end{array}$} & \multirow[t]{2}{*}{ Outcomes } \\
\hline & & Mean age (years) & No. of patients $(n)$ & Female & $\mathrm{BMI}$ & & & \\
\hline $\mathrm{Hu}[24]$ & China & $58.2 / 59.3$ & $110 / 98$ & $68 / 58$ & $25.8 / 25.6$ & Prospective & NC & $5,7,10,13,14$ \\
\hline Siljander [31] & USA & $65 / 64$ & $1846 / 3162$ & 1002/1799 & $27.4 / 30.2$ & Retrospective & 3 & $1,4,5,6,7,10,12$ \\
\hline Wu [32] & China & $49.67 / 48.21$ & $24 / 23$ & $9 / 10$ & $22.16 / 23.32$ & Retrospective & 15 & $1,2,3,4,13,14,15$ \\
\hline Barrett [20] & USA & NC & $43 / 44$ & NC & NC & RCT & 60 & 15,17 \\
\hline Daas [33] & Netherlands & $74.8 / 72.1$ & $41 / 26$ & $33 / 22$ & $27.6 / 28.1$ & Retrospective & 12 & 17 \\
\hline Fleischman [34] & USA & $62.7 / 66.6$ & $5465 / 2160$ & $2815 / 1164$ & $28.4 / 28.8$ & Retrospective & 24 & 5,7 \\
\hline Godoy-Monzon [25] & Argentina & $56.1 / 57.2$ & $40 / 40$ & $17 / 15$ & NC & Prospective & 17.6 & $1,4,9,15$ \\
\hline Triantafyllopoulos [35] & USA & $62.3 / 64.2$ & $1182 / 18853$ & $626 / 10126$ & NC & Retrospective & 50 & 3 \\
\hline Lee [36] & Korea & $65.4 / 68.4$ & $12 / 13$ & NC & NC & Retrospective & 1.5 & $1,2,9$ \\
\hline Rykov [21] & Netherlands & $62.8 / 60.2$ & $23 / 23$ & $15 / 12$ & $29 / 29.3$ & RCT & 1.5 & $1,2,3,15,17$ \\
\hline Zhao [22] & China & $64.88 / 62.18$ & $60 / 60$ & $36 / 34$ & $24.35 / 25.58$ & RCT & 6 & $1,2,3,4,5,13,14,15,16$ \\
\hline Fransen [37] & Netherlands & $64.2 / 62.6$ & $45 / 38$ & $30 / 24$ & $25 / 27.6$ & Retrospective & 12 & $1,2,3,14$ \\
\hline Jelsma [26] & Netherlands & $66.7 / 67.9$ & $87 / 32$ & $48 / 16$ & $26.6 / 28$ & Prospective & 6 & $3,5,6,7,8,10,11,16,17$ \\
\hline Langlois [27] & France & $86 / 85$ & $38 / 44$ & $32 / 19$ & $21 / 23$ & Prospective & 1.5 & $1,3,7,9$ \\
\hline Amlie [38] & Norway & $67 / 66$ & $421 / 421$ & $291 / 268$ & NC & Prospective & 36 & 7,12 \\
\hline Barrett [23] & USA & $61.4 / 63.2$ & $43 / 44$ & $14 / 25$ & $30.7 / 29.1$ & RCT & 12 & $1,2,4,5,7,8,13,14,15,16,17$ \\
\hline Nam [39] & USA & $66.76 / 66.86$ & $110 / 110$ & $71 / 65$ & $28.3 / 27.4$ & Retrospective & 6 & 13,14 \\
\hline Spaans [40] & Netherlands & $69 / 68$ & $46 / 46$ & $22 / 32$ & $25 / 29$ & Retrospective & 12 & $1,2,3,5,7,9,11,14$ \\
\hline
\end{tabular}

NC not clear

1. operative time; 2 . intraoperative blood loss; 3. length of hospital stay; 4. incision length; 5 . fracture; 6. infection; 7. dislocation; 8. hematoma; 9. LLD (leg-length difference); 10. PE/DVT (pulmonary embolism/deep vein thrombosis); 11. pneumonia; 12. re-operation; 13. anteversion angle. 14. abduction angle; 15. HHS (Harris hip score); 16. VAS (visual analog scale); 17. HOOS (hip disability and osteoarthritis outcome)

complications in DAA is relatively high, especially during early technical learning stages [16-19].

Several more high-quality RCT [20-23] and non-RCTs [24-27] have been published without conclusive results. Although these literatures hold many new views, it is necessary to analyze this issue because of their single demonstration, a one-sided focus on clinical results, lack of latest data, and lack of recommendation strength. Jia et al. [28] performed a meta-analysis, he compared the two approaches of DAA and PA. However, PA includes PLA, so his inclusion criteria were wider and biased.
Wang et al. [29] analyzed the results of DAA and LA, nevertheless, LA is not PLA. Although they conclude that DAA has good results in many aspects, the results of DAA compared with PLA require further study.

\section{Methods}

Our study was based on the PRISMA guidelines (the preferred reporting item for systematic review and metaanalysis) [30]. This meta-analysis was prospectively registered with Prospero International prospective register

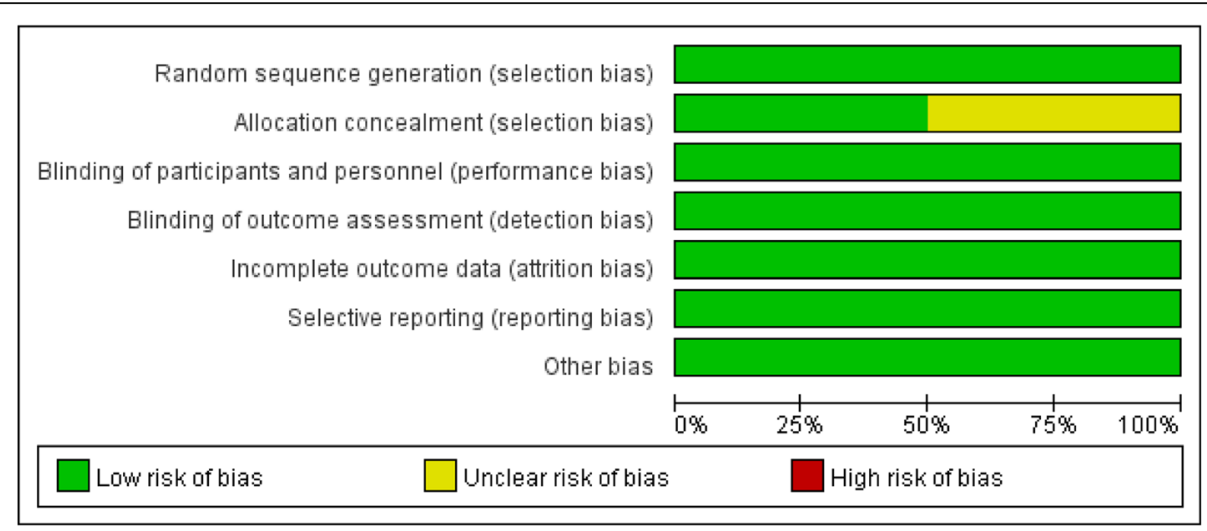

Fig. 2 Risk of bias graph: review authors' judgments about each risk of bias item presented as percentages across all included studies 


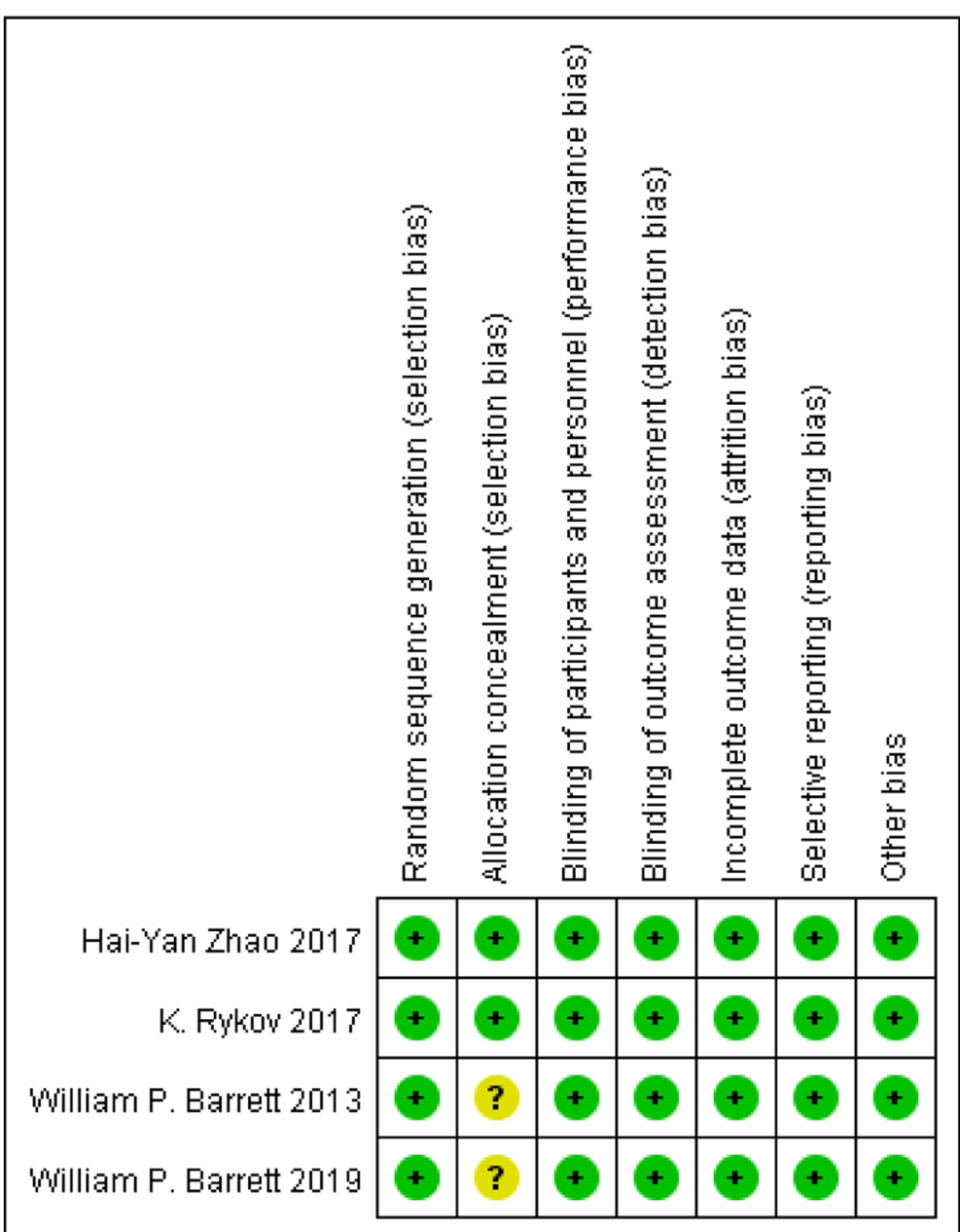

Fig. 3 Risk of bias summary for included studies. +, no bias; -, bias; ?, bias unknown

Table 2 The literatures quality of cohort studies were evaluated using Newcastle-Ottawa scale

\begin{tabular}{|c|c|c|c|c|c|}
\hline Author/year & Selection & Comparability & Outcome & Total & Rating \\
\hline Hu et al. & 3 & 2 & 3 & 8 & Excellent \\
\hline Siljander et al. & 3 & 2 & 3 & 8 & Excellent \\
\hline Wu et al. & 3 & 0 & 3 & 6 & Good \\
\hline Daas et al. & 3 & 2 & 3 & 8 & Excellent \\
\hline Fleischman et al. & 3 & 2 & 3 & 8 & Excellent \\
\hline Godoy-Monzon et al. & 4 & 1 & 3 & 8 & Excellent \\
\hline Triantafyllopoulos et al. & 3 & 2 & 3 & 8 & Excellent \\
\hline Lee et al. & 3 & 1 & 3 & 7 & Good \\
\hline Fransen et al. & 3 & 2 & 3 & 8 & Excellent \\
\hline Jelsma et al. & 4 & 2 & 3 & 9 & Excellent \\
\hline Langlois et al. & 4 & 2 & 3 & 9 & Excellent \\
\hline Amlie et al. & 4 & 2 & 3 & 9 & Excellent \\
\hline Nam et al. & 3 & 2 & 3 & 8 & Excellent \\
\hline Spaans et al. & 3 & 1 & 3 & 7 & Good \\
\hline
\end{tabular}




\begin{tabular}{|c|c|c|c|c|c|c|c|c|c|c|c|c|}
\hline \multirow[b]{2}{*}{ Studv or Subgroup } & \multicolumn{3}{|c|}{ DAA } & \multicolumn{3}{|c|}{ PLA } & \multicolumn{3}{|c|}{ Mean Difference } & \multirow{2}{*}{\multicolumn{3}{|c|}{$\begin{array}{c}\text { Mean Difference } \\
\text { N, Random, } 95 \% \mathrm{Cl}\end{array}$}} \\
\hline & Mean & SD & Total & Mean & SD & Total & Weight & IV, Random, $95 \% \mathrm{Cl}$ & Year & & & \\
\hline Han Wu 2020 & 122.47 & 25.4 & 24 & 138.47 & 24.45 & 23 & $8.4 \%$ & $-16.00[-30.25,-1.75]$ & 2020 & & & \\
\hline Matthew Siljander 2020 & 95 & 18 & 1846 & 71 & 26 & 3162 & $11.9 \%$ & $24.00[22.78,25.22]$ & 2020 & & & - \\
\hline D.Gadoy-Manzon 2019 & 62 & 8.58 & 40 & 63 & 8.12 & 40 & $11.6 \%$ & $-1.00[-4.66,2.66]$ & 2019 & & & \\
\hline Hai-Yan Zhao 2017 & 83.26 & 6.69 & 60 & 65.48 & 13.32 & 60 & $11.6 \%$ & $17.78[14.01,21.55]$ & 2017 & & & $=$ \\
\hline Sang-Hong Lee 2017 & 110 & 66 & 12 & 88 & 67 & 13 & $1.8 \%$ & $22.00[-30.16,74.16]$ & 2017 & & & \\
\hline K. Rykov 2017 & 71 & 7 & 23 & 62 & 7 & 23 & $11.6 \%$ & $9.00[4.95,13.05]$ & 2017 & & & $\rightarrow$ \\
\hline Bas Fransen 2016 & 75 & 29.28 & 45 & 55 & 10.53 & 38 & $10.2 \%$ & $20.00[10.81,29.19]$ & 2016 & & & \\
\hline Jean Langlois 2015 & 65 & 12 & 38 & 54 & 15 & 44 & $11.2 \%$ & $11.00[5.15,16.85]$ & 2015 & & & - \\
\hline William P.Barrett 2013 & 84.3 & 12.4 & 43 & 60.5 & 12.4 & 44 & $11.3 \%$ & $23.80[18.59,29.01]$ & 2013 & & & $\rightarrow$ \\
\hline Anne J Spaans 2012 & 84 & 28 & 46 & 46 & 9 & 46 & $10.4 \%$ & $38.00[29.50,46.50]$ & 2012 & & & \\
\hline Total $(95 \% \mathrm{Cl})$ & & & 2177 & & & 3493 & $100.0 \%$ & $14.81[7.18,22.44]$ & & & & \\
\hline \multicolumn{10}{|c|}{$\begin{array}{l}\text { Heterogeneity: } \text { Tau }^{2}=126.88 ; \mathrm{Chi}^{2}=249.91, \mathrm{df}=9(\mathrm{P}=0.00001) ; \mathrm{I}^{2}=96 \% \\
\text { Test for overall effect: } Z=3.80(P=0.0001)\end{array}$} & -50 & $\begin{array}{ll}-25 & 0 \\
\text { ours }[D A A]\end{array}$ & $25 \quad 50$ \\
\hline
\end{tabular}

Fig. 4 Forest plot comparing the operative time of DAA and PLA

of systematic reviews (www.crd.york.ac.uk/prospero/) (Registration ID: CRD42020151208).

\section{Literature search}

In this systematic review and meta-analysis, we searched Cochrane Library, Web of Science, and PubMed for comparative studies of DAA and PLA. With the following search terms: (1) "total hip arthroplasty (All Fields)" OR "total hip replacement (All Fields)" OR “THA (All Fields)"; (2) "direct anterior approach (All Fields)" OR "DAA (All Fields)"; (3) "posterolateral approach (All Fields)" OR "PLA (All Fields)" OR "posterior approach (All Fields)" OR "PA (All Fields)"; (4) (1) AND (2) AND (3). We got the literatures we need by reading the title, abstract, and complete manuscript. We stipulated that the search of the literatures were not restricted by language. Reference list of relevant meta-analyses was queried to obtain studies that might have been missed.

\section{Inclusion criteria}

Inclusion criteria for this meta-analysis followed the participant, intervention, comparison, and outcomes (PICO) approach.

1. Participant: patients who were willing to undergo primary total hip arthroplasty

2. Intervention: patients who underwent direct anterior approach

3. Comparison: patients who underwent posterolateral approach

4. Outcomes: we stipulated that inclusion in the literatures should include at least any of the following results. (1) Primary outcomes: HHS (Harris hip score), VAS (visual analog scale), HOOS (hip disability and osteoarthritis outcome), operation time, intraoperative blood loss, length of hospital stay; (2) secondary outcomes: incision length, fracture, infection, PE/DVT (pulmonary embolism/deep vein thrombosis), pneumonia, dislocation, hematoma,

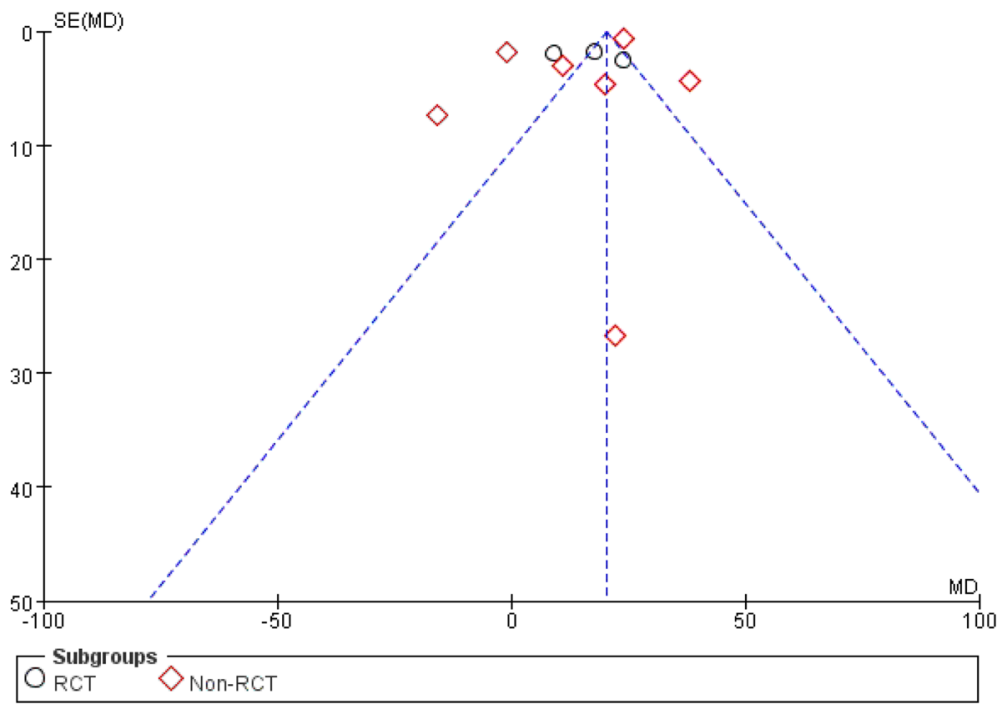

Fig. 5 Funnel plots used to describe heterogeneity between RCT and non-RCT 


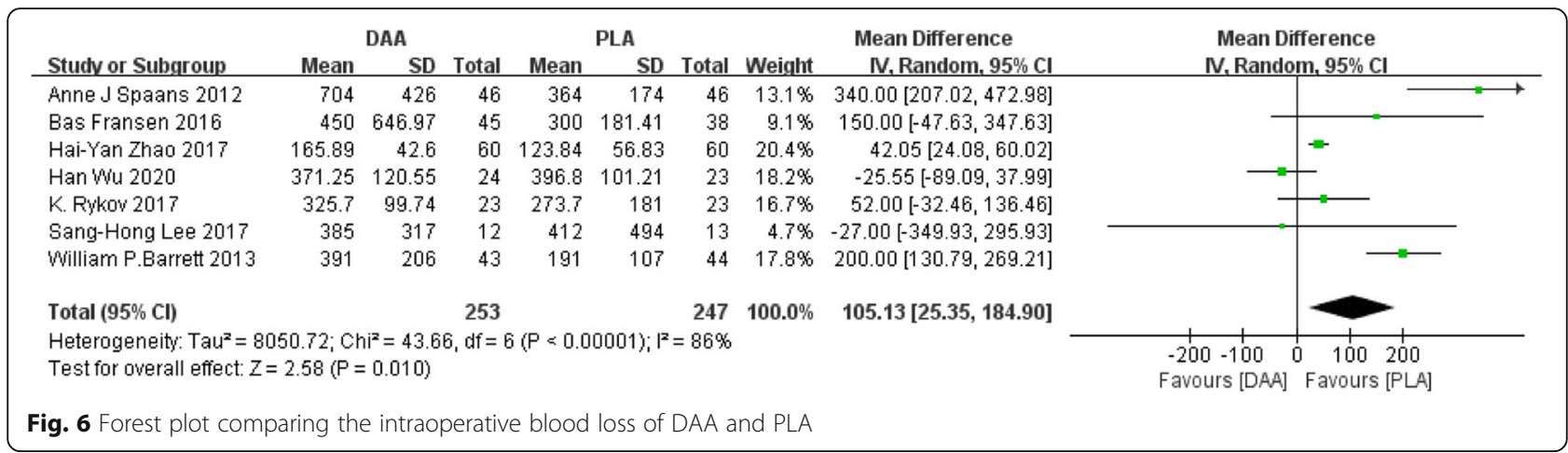

LLD (leg-length difference), re-operation, abduction angle, anteversion angle

5. Study design: RCT or high-quality non-RCT

\section{Exclusion criteria}

1. Simple studies of methods for DAA or PLA without comparative analysis

2. No relevant literature data information

3. Repeated reports and reviews

\section{Study selection}

Two professionally trained researchers (YZ, JNS) independently screened the literatures and extracted the information. In case of any disagreement, discuss or submit it to a third party (YZ) who has received professional training. We expurgated duplicate literatures using the delete option of the software Endnote X9. On the basis of the criteria, we picked the studies out we needed and acquired the full text to extract the data, then read the title and abstract of the literatures to exclude the literature that did not match the study subjects, study type, and intervention measures. Literatures accorded with the inclusion criteria were further read literature content, excluding those that were repeatedly published, with incomplete data and poor credibility.

\section{Data extraction}

Data from literatures were independently drawn by two investigators. By discussing with third parties, we resolved the extraction differences between the two researchers. The indexes extracted by the two researchers included basic information (author, country, sample size, age, BMI, study type, follow-up), score (HHS, VAS, HOOS), operation time, intraoperative blood loss, length of hospital stay, incision length, re-operation, complications (fracture, infection, PE/DVT, pneumonia, dislocation, haematoma), LLD, radiographic outcome (abduction angle, anteversion angle).

\section{Assessment of methodological quality}

Cochrane risk assessment criteria were applied to estimate the literatures quality of the included RCTs: selection methods of the case group and control group, comparability between groups and exposure assessment methods; the literatures quality of non-RCTs were evaluated putting the Newcastle-Ottawa scale (NOS) into use, with a full score of $9, \geq 7$ for high quality literature, 5 to 6 for medium quality literature, and $<5$ for low quality literature.

\section{Statistical analysis}

Review Manager 5.3 was adopted for the analysis of included literatures data and a $P$ value of $<0.05$ in the data

\begin{tabular}{|c|c|c|c|c|c|c|c|c|c|c|c|c|}
\hline Studv or Subgroup & \multicolumn{3}{|c|}{ DAA } & \multicolumn{3}{|c|}{ PLA } & Weight & $\begin{array}{l}\text { Mean Difference } \\
\text { IV, Random, } 95 \% \mathrm{Cl}\end{array}$ & \multicolumn{4}{|c|}{$\begin{array}{c}\text { Mean Difference } \\
\text { IV, Random, 95\% Cl }\end{array}$} \\
\hline Anne J Spaans 2012 & 4.8 & 2 & 46 & 4.7 & 2.1 & 46 & $10.4 \%$ & $0.10[-0.74,0.94]$ & & & & \\
\hline Bas Fransen 2016 & 4 & 1.14 & 45 & 4 & 3.04 & 38 & $8.0 \%$ & $0.00[-1.02,1.02]$ & & & & \\
\hline Geargios K Triantafyllopoulos 2019 & 2.4 & 1.1 & 1182 & 3.3 & 1.6 & 18853 & $26.6 \%$ & $-0.90[-0.97,-0.83]$ & & - & & \\
\hline Hai-Yan Zhao 2017 & 2.8 & 0.16 & 60 & 3.3 & 0.37 & 60 & $26.2 \%$ & $-0.50[-0.60,-0.40]$ & & $\because$ & & \\
\hline Han Wu 2020 & 9.59 & 4.62 & 24 & 12.08 & 3.58 & 23 & $2.0 \%$ & $-2.49[-4.85,-0.13]$ & 4 & & & \\
\hline Jean Langlois 2015 & 10 & 3.3 & 38 & 8.7 & 4 & 44 & $4.0 \%$ & $1.30[-0.28,2.88]$ & & & & \\
\hline Jetse Jelsma 2016 & 3.08 & 1.41 & 87 & 5.45 & 5.25 & 32 & $3.1 \%$ & $-2.37[-4.21,-0.53]$ & & & & \\
\hline K. Rykov 2017 & 1.5 & 0.7 & 23 & 1.5 & 0.7 & 23 & $19.6 \%$ & $0.00[-0.40,0.40]$ & & & - & \\
\hline Total $(95 \% \mathrm{Cl})$ & & & 1505 & & & 19119 & $100.0 \%$ & $-0.43[-0.78,-0.09]$ & & & & \\
\hline $\begin{array}{l}\text { Heterogeneity: } \operatorname{Tau}^{2}=0.12 ; \mathrm{Chi}^{2}=73 \\
\text { Test for overall effect: } \mathrm{Z}=2.44(\mathrm{P}=0\end{array}$ & $\begin{array}{l}\text { 11, } d f=7 \\
1 \text { 1) }\end{array}$ & $7(P \leq 0$ & 0.0000 & 1); $\left.\right|^{2}=90$ & $00 \%$ & & & & $\frac{1}{-4}$ & $\stackrel{-1}{-2}_{\text {Favours [DAA] }}^{1}$ & $\frac{1}{2}$ & $\frac{1}{4}$ \\
\hline
\end{tabular}




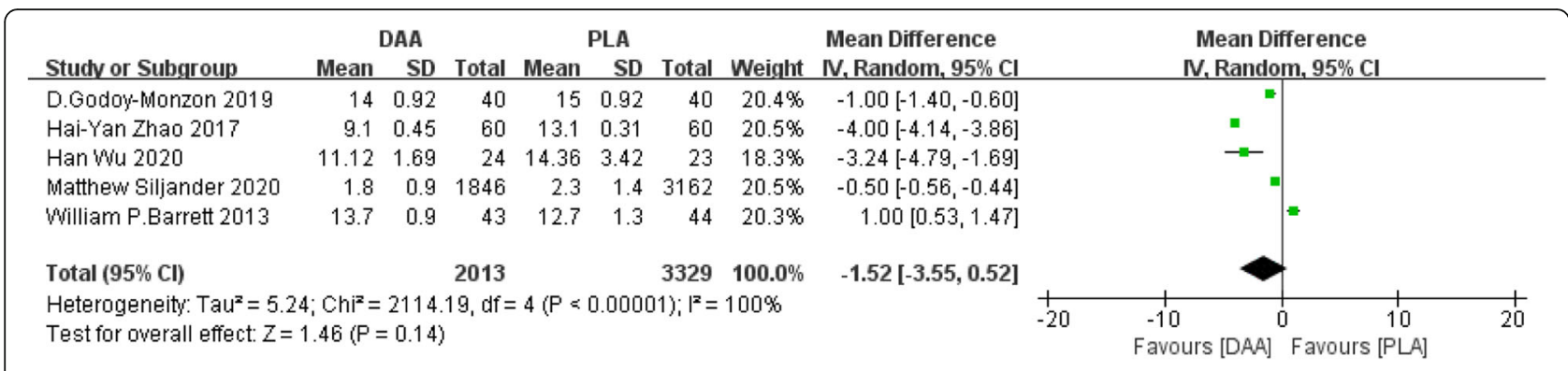

Fig. 8 Forest plot comparing the incision length of DAA and PLA

were defined as statistically significant. Dichotomous variables were applied using the odds ratio (OR) and 95\% confidence interval (CI), while continuous variables were applied using weighted mean difference (WMD) and 95\% CI. Performed a sensitivity analysis by deleting one study every time and rebuilding the data from the remaining studies to identify possible high heterogeneity studies. Funnel plot was drawn to test whether there was deviation in the included literatures.

\section{Results}

\section{Study characteristics and quality evaluation}

A total of 572 literatures were retrieved according to the search term. After deleting the duplicates using the software Endnote X9, 323 remained. Based on the specified inclusion and exclusion criteria, 292 articles were precluded. We perused the remaining 31 articles, 2 of which were systematic reviews. We excluded another 13 articles for the following reasons: no required data $(n=5)$; not unilateral THA $(n=4)$; review $(n=2)$; others $(n=2)$. Finally, this meta-analysis totally absorbed $18 \mathrm{RCT}$ and non-RCTs. Literatures choice process was shown in Fig. 1.

Table 1 lists in detail the general characteristics of the studies after the final selection. Eighteen studies totaling 34,848 patients $(\mathrm{DAA}=9624$, PLA $=25,224$ ) were contained. Four RCTs were low risk evaluated by Cochrane Collaboration risk of bias assessment tool, four prospective and ten retrospective cohort studies were high or middle quality evaluated by the NewcastleOttawa scale risk of bias assessment tool. We included relevant studies from 2012 to 2020 . The sample size in the literatures were at least 25 , at most 20,035. The follow-up time varies from 1.5 to 60 months.

\section{Risk of bias}

Risk of bias graph and risk of bias summary of the randomized controlled study literatures are apart shown in Figs. 2 and 3. Four of these studies described the generation of random sequences, performance, and detection bias. Two studies described allocation concealment. Attrition bias, reporting bias, and other biases in the literatures were reported in detail, and these were classified as low-risk deviations. The literatures quality of the cohort study was appraised using the Newcastle-Ottawa scale. Table 2 presents the risk of assessing quality bias in the methodology of non-randomized controlled trials, and the results showed that the risk of bias was relatively low.

\section{Outcomes}

\section{Operative time}

Ten studies [21, 22, 23, 25, 27, 31, 32, 36, 37, 40] (including 5670 participants) reported a comparison of operative time between the two approaches, and the results

\begin{tabular}{|c|c|c|c|c|c|c|c|c|c|c|}
\hline Studv or Subgroup & $\begin{array}{r}\text { DAA } \\
\text { Events }\end{array}$ & Total & $\begin{array}{l}\text { PLA } \\
\text { Events }\end{array}$ & Total & Weight & $\begin{array}{c}\text { Odds Ratio } \\
\text { M-H, Fixed, 95\% Cl }\end{array}$ & \multicolumn{4}{|c|}{$\begin{array}{c}\text { Odds Ratio } \\
\text { M-H, Fixed, 95\% Cl }\end{array}$} \\
\hline Andrew N. Fleischman 2019 & 48 & 5465 & 8 & 2160 & $24.4 \%$ & $2.38[1.13,5.05]$ & & & $\longrightarrow$ & \\
\hline Anne J Spaans 2012 & 2 & 46 & 2 & 46 & $4.1 \%$ & $1.00[0.13,7.42]$ & & & & \\
\hline Fei Hu 2020 & 4 & 110 & 3 & 98 & $6.6 \%$ & $1.19[0.26,5.48]$ & & & & \\
\hline Hai-Yan Zhao 2017 & 1 & 60 & 0 & 60 & $1.0 \%$ & $3.05[0.12,76.39]$ & & & & \\
\hline Jetse Jelsma 2016 & 1 & 87 & 0 & 32 & $1.5 \%$ & $1.13[0.04,28.38]$ & & & & \\
\hline Matthew Siljander 2020 & 26 & 1846 & 38 & 3162 & $59.2 \%$ & $1.17[0.71,1.94]$ & & & - & \\
\hline William P.Barrett 2013 & 0 & 43 & 1 & 44 & $3.1 \%$ & $0.33[0.01,8.41]$ & & & & \\
\hline Total $(95 \% \mathrm{Cl})$ & & 7657 & & 5602 & $100.0 \%$ & $1.46[1.00,2.11]$ & & & & \\
\hline Total events & 82 & & 52 & & & & & & & \\
\hline $\begin{array}{l}\text { Heterogeneity: } \text { Chi }^{2}=3.59 \text { d } \\
\text { Test for overall effect: } Z=1.9\end{array}$ & $\begin{array}{l}6(P=0 \\
(P=0.05)\end{array}$ & $73) ; 1^{2}=$ & $=0 \%$ & & & & 0.01 & $\begin{array}{l}0.1 \\
\text { Favours [DAA] }\end{array}$ & $1 \frac{10}{\text { Favours }[\mathrm{PLA}]}$ & 100 \\
\hline
\end{tabular}




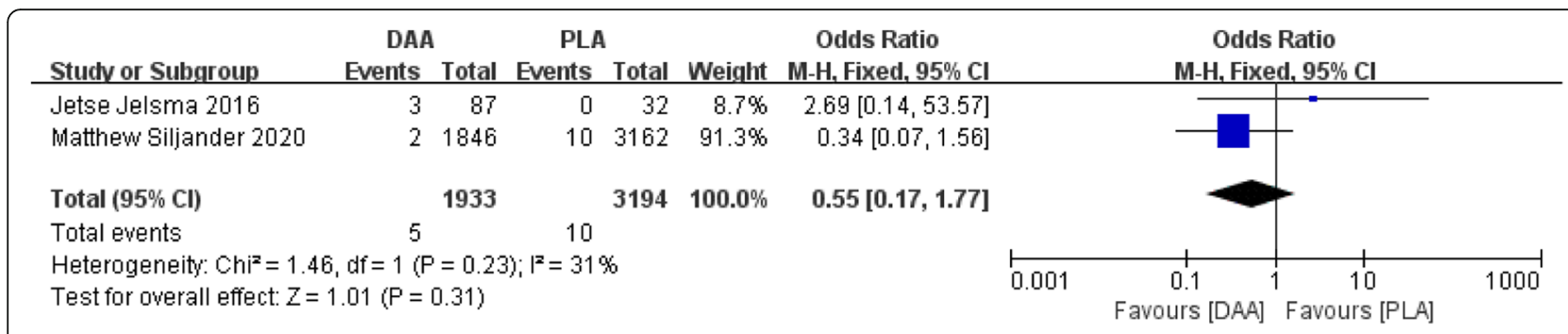

Fig. 10 Forest plot comparing the infection of DAA and PLA

obtained can prove that the operation time of PLA was less than that of DDA (Fig. 4). This project involved 10 of the 18 studies. We conducted a subgroup analysis and divided it into RCT and non-RCTs. As shown in the funnel plots, studies were basically symmetrical, indicating a small deviation (Fig. 5).

\section{Intraoperative blood loss}

Seven studies [21-23, 32, 36, 37, 40] (500 participants in total) recorded intraoperative blood loss for both surgical approaches, and the results obtained can prove that the intraoperative blood loss of PLA was less than that of DAA (Fig. 6).

\section{Length of hospital stay}

Eight studies [21, 22, 26, 27, 32, 35, 37, 40] (20623 participants) reported a comparison of length of hospital stay after THA. The results obtained can prove that DAA had a shorter length of hospital stay (Fig. 7).

\section{Incision length}

Five studies [22, 23, 25, 31, 32] (5342 participants) reported a comparison of incision length after two types of surgery. The results obtained can prove that there was no significant difference in incision length after the two surgeries $(\mathrm{WMD}=-1.52,95 \% \mathrm{CI}-3.55$ to $0.52, P=$ 0.14, Fig. 8).

\section{Fracture}

Seven studies [22-24, 26, 31, 34, 40] (13,259 participants) reported a comparison of the incidence of fractures after the two surgeries, and the results obtained can prove that PLA has a higher fracture rate in patients than DAA (Fig. 9).

\section{Infection}

Two studies [26, 31] (5127 participants) reported a comparison of infection rates after the two surgeries, and results obtained can prove that there was no significant difference in infection rate between the two operations $(\mathrm{OR}=0.55,95 \% \mathrm{CI} 0.17$ to $1.77, P=0.31$, Fig. 10).

\section{Dislocation}

Eighteen studies [23, 24, 26, 27, 31, 34, 38, 40] $(14,063$ participants) reported a comparison of hip dislocation after two types of surgery, showing PLA has a lower hip dislocation rate than DAA (Fig. 11).

\begin{tabular}{|c|c|c|c|c|c|c|c|c|c|c|}
\hline Studv or Subgroup & $\begin{array}{l}\text { DAA } \\
\text { Events }\end{array}$ & A & \multicolumn{2}{|c|}{ PLA } & Weight & $\begin{array}{c}\text { Odds Ratio } \\
\text { M-H, Fixed, 95\% Cl }\end{array}$ & \multicolumn{4}{|c|}{$\begin{array}{c}\text { Odds Ratio } \\
\text { M-H, Fixed, 95\% Cl }\end{array}$} \\
\hline Andrew N. Fleischman 2019 & 40 & 5465 & 38 & 2160 & $54.8 \%$ & $0.41[0.26,0.64]$ & & & & \\
\hline Anne J Spaans 2012 & 1 & 46 & 1 & 46 & $1.0 \%$ & $1.00[0.06,16.48]$ & & & & \\
\hline Einar Amlie 2014 & 10 & 421 & 13 & 421 & $12.9 \%$ & $0.76[0.33,1.76]$ & & 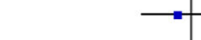 & - & \\
\hline Fei Hu 2020 & 0 & 110 & 1 & 98 & $1.6 \%$ & $0.29[0.01,7.30]$ & & & & \\
\hline Jean Langlois 2015 & 1 & 38 & 9 & 44 & $8.2 \%$ & $0.11[0.01,0.87]$ & & & & \\
\hline Jetse Jelsma 2016 & 1 & 87 & 1 & 32 & $1.5 \%$ & $0.36[0.02,5.94]$ & & & & \\
\hline Watthew Siljander 2020 & 5 & 1846 & 25 & 3162 & $18.6 \%$ & $0.34[0.13,0.89]$ & & $\longrightarrow$ & & \\
\hline Milliam P.Barrett 2013 & 0 & 43 & 1 & 44 & $1.5 \%$ & $0.33[0.01,8.41]$ & & & & \\
\hline Total $(95 \% \mathrm{Cl})$ & & 8056 & & 6007 & $100.0 \%$ & $0.42[0.30,0.59]$ & & & & \\
\hline Total events & 58 & & 89 & & & & & & & \\
\hline $\begin{array}{l}\text { Heterogeneity: } \mathrm{Chi}^{2}=4.24, \mathrm{df}= \\
\text { Test for owerall effect: } Z=4.89\end{array}$ & $\begin{array}{l}7(P=0 \\
(P<0.000\end{array}$ & $\begin{array}{l}\text { 75); }\left.\right|^{2}= \\
001)\end{array}$ & $=0 \%$ & & & & 0.002 & $\begin{array}{c}0.1 \\
\text { Favours [DAA] }\end{array}$ & Favours [PLA] & 500 \\
\hline
\end{tabular}




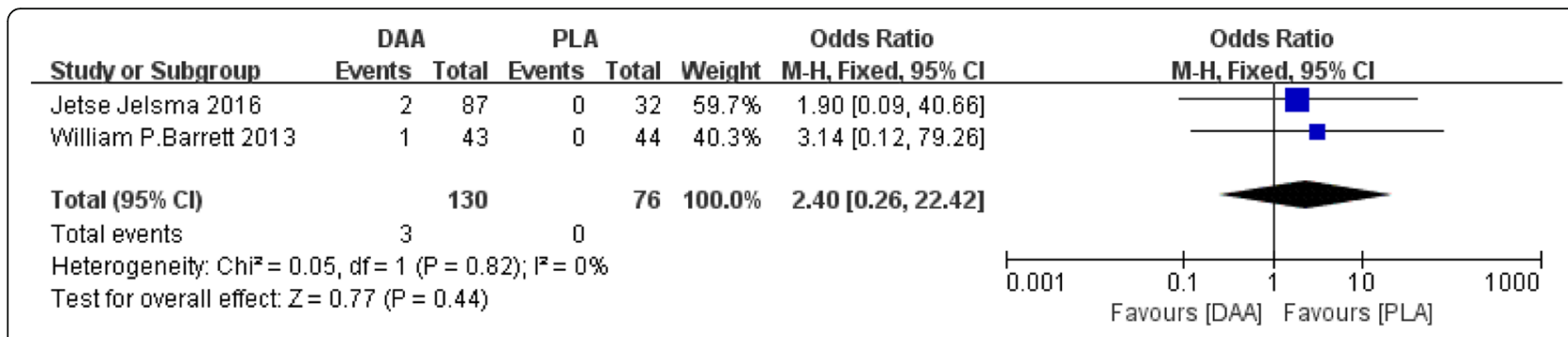

Fig. 12 Forest plot comparing the hematoma of DAA and PLA

\section{Hematoma}

Two studies [23, 26] (206 participants) reported a comparison of the hematoma rate after the two surgeries. The results obtained can prove that the difference was no statistically significant $(\mathrm{OR}=2.40,95 \% \mathrm{CI} 0.26$ to 22.42, $P=0.44$, Fig. 12).

\section{LLD}

Two studies [25, 36] (105 participants) reported a comparison of LLD between the two surgeries. Results showed that LLD after DAA surgery was less than PLA surgery (Fig. 13).

\section{PE/DVT}

Three studies [24, 26, 31] (5235 participants) reported a comparison of PE/DVT between the two surgeries. Results showed that PE/DVT after DAA surgery was less than PLA surgery (Fig. 14).

\section{Pneumonia}

Two studies [26, 40] (211 participants) reported a comparison of pneumonia between the two surgeries. Results showed that there was no significant difference in pneumonia (OR $=1.91,95 \%$ CI 0.20 to $18.60, P=0.58$, Fig. 15$)$.

\section{Re-operation}

Two studies [31, 38] (with a total of 5850 participants) reported a comparison of the incidence of re-operation after the two surgeries, and the results obtained can prove that there was no significant difference in the incidence of re-operation $(\mathrm{OR}=1.61,95 \% \mathrm{CI} 0.93$ to $2.77, P$ $=0.09$, Fig. 16).

\section{Anteversion angle}

Five studies [22-24, 32, 39] (682 participants) reported a comparison of the anteversion angle after two types of surgery. The results obtained can prove that there was no statistically significant difference between the two postoperative anteversion angles (WMD $=-1.57,95 \% \mathrm{CI}$ -6.12 to $2.99, P=0.50$, Fig. 17$)$.

\section{Abduction angle}

Seven studies [22-24, 32, 37, 39, 40] (857 participants) reported a comparison of the abduction angle after two types of surgery. The results obtained can prove that there was no statistically significant difference between the two postoperative abduction angles (WMD $=-0.70$, $95 \%$ CI -2.53 to $1.12, P=0.45$, Fig. 18$)$.

\section{HHS}

Harris hip score (HHS) [20-23, 25, 32] was divided into three subgroups $(<3 \mathrm{~m},<6 \mathrm{~m},<12 \mathrm{~m})$ according to the evaluation time. Six studies (1048 participants) were contained. The results indicated that the three periods of HHS of DAA were superior to that of PLA (Fig. 19).

\section{VAS}

Visual analog scale (VAS) [22, 23, 26] was divided into two subgroups according to time: VAS at 24 and $48 \mathrm{~h}$. Three studies (533 participants) were contained. The results obtained can prove that the pain was lighter and relieved faster than that of PLA in 24 or $48 \mathrm{~h}$ after DAA (Fig. 20).

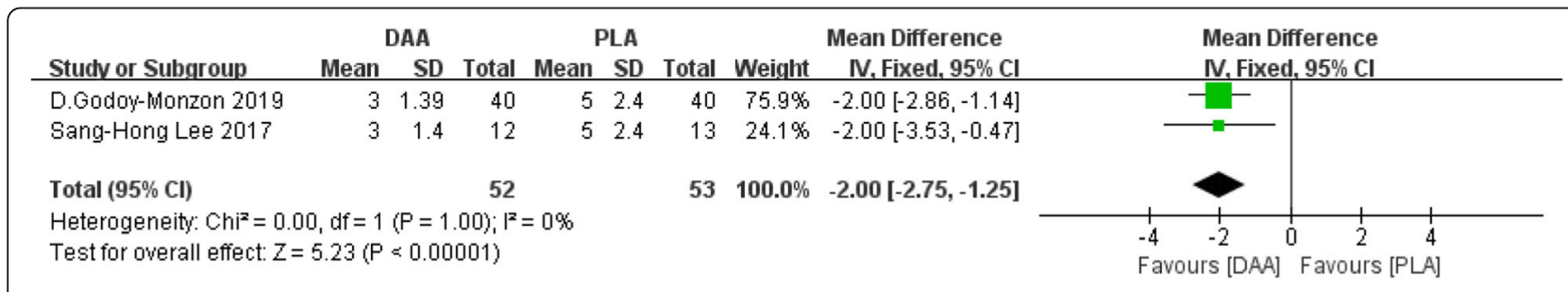

Fig. 13 Forest plot comparing the LLD of DAA and PLA 


\begin{tabular}{|c|c|c|c|c|c|c|c|c|c|c|}
\hline Studv or Subgroup & \multicolumn{2}{|c|}{ Experimental } & \multicolumn{2}{|c|}{ Control } & Weight & $\begin{array}{c}\text { Odds Ratio } \\
\text { M-H, Fixed, 95\% Cl }\end{array}$ & \multicolumn{4}{|c|}{$\begin{array}{c}\text { Odds Ratio } \\
\text { M-H, Fixed, 95\% Cl }\end{array}$} \\
\hline Fei Hu 2020 & 2 & 110 & 4 & 98 & $19.7 \%$ & $0.44[0.08,2.43]$ & & $=$ & + & \\
\hline Jetse Jelsma 2016 & 1 & 87 & 0 & 32 & $3.4 \%$ & $1.13[0.04,28.38]$ & & & & \\
\hline Matthew Siljander 2020 & 4 & 1846 & 22 & 3162 & $76.9 \%$ & $0.31[0.11,0.90]$ & & & & \\
\hline Total $(95 \% \mathrm{Cl})$ & & 2043 & & 3292 & $100.0 \%$ & $0.36[0.15,0.85]$ & & & & \\
\hline Total events & 7 & & 26 & & & & & & & \\
\hline $\begin{array}{l}\text { Heterogeneity: } \mathrm{Chi}^{2}=0 . \\
\text { Test for overall effect: } Z=\end{array}$ & $\begin{array}{l}\mathrm{df}=2(\mathrm{P} \\
2.33(\mathrm{P}=0\end{array}$ & $\begin{array}{l}=0.74) ; \\
02)\end{array}$ & $\left.\right|^{2}=0 \%$ & & & & 0.01 & $\begin{array}{l}0.1 \\
\text { Favours [DAA] }\end{array}$ & $\begin{array}{l}1 \\
\text { Favours [PLA] }\end{array}$ & 100 \\
\hline
\end{tabular}

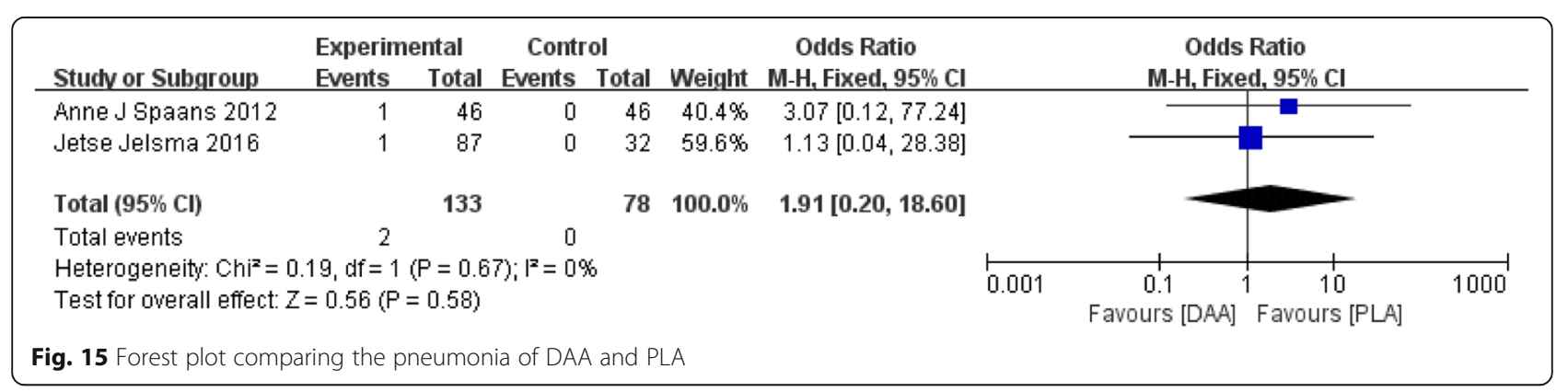

\begin{tabular}{|c|c|c|c|c|c|c|c|c|c|c|}
\hline Studv or Subgroup & \multicolumn{2}{|c|}{ Experimental } & \multicolumn{2}{|c|}{ Control } & Weight & $\begin{array}{c}\text { Odds Ratio } \\
\text { M-H, Fixed, } 95 \% \mathrm{Cl}\end{array}$ & \multicolumn{4}{|c|}{$\begin{array}{c}\text { Odds Ratio } \\
\text { M-H, Fixed, } 95 \% \mathrm{Cl}\end{array}$} \\
\hline Einar Amlie 2014 & 13 & 421 & 12 & 421 & $57.0 \%$ & $1.09[0.49,2.41]$ & & & & \\
\hline Matthew Siljander 2020 & 16 & 1846 & 12 & 3162 & $43.0 \%$ & $2.30[1.08,4.86]$ & & & 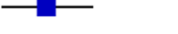 & \\
\hline Total $(95 \% \mathrm{Cl})$ & & 2267 & & 3583 & $100.0 \%$ & $1.61[0.93,2.77]$ & & & & \\
\hline Total events & 29 & & 24 & & & & & & & \\
\hline $\begin{array}{l}\text { Heterogeneity: } \mathrm{Chi}^{2}=1.8 \\
\text { Test for overall effect: } Z=\end{array}$ & $\begin{array}{l}, d f=1(P \\
1.71(P=\end{array}$ & $\begin{array}{l}=0.18) \text {; } \\
09)\end{array}$ & $\left.\right|^{2}=44 \%$ & & & & 0.01 & $\begin{array}{c}0.1 \\
\text { Favours [DAA] }\end{array}$ & $\begin{array}{c}10 \\
\text { Favours [PLA] }\end{array}$ & 100 \\
\hline
\end{tabular}

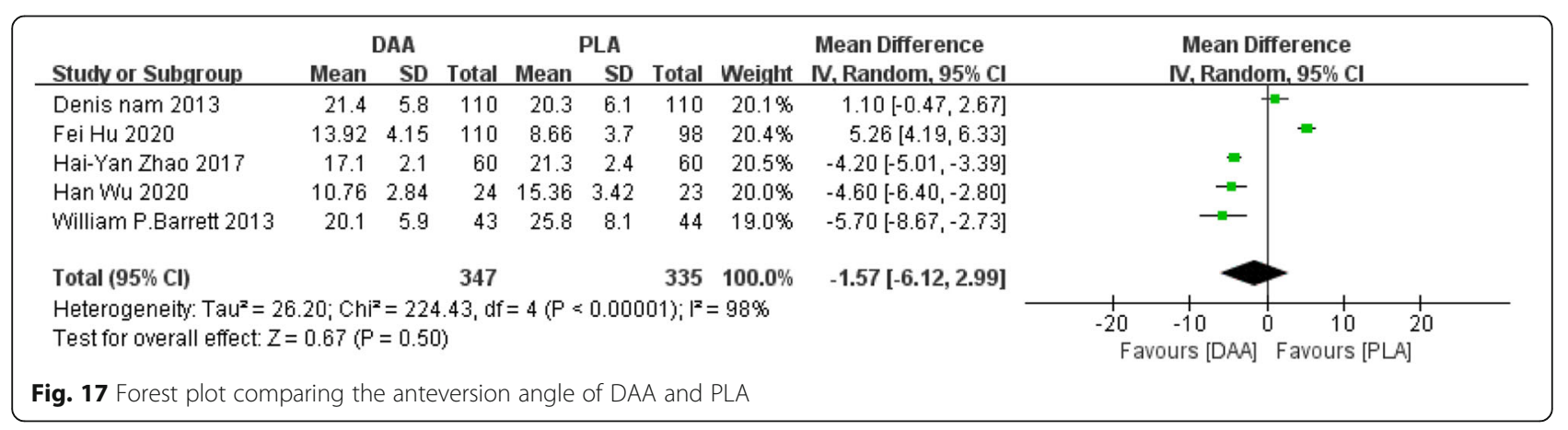




\begin{tabular}{|c|c|c|c|c|c|c|c|c|c|}
\hline \multirow[b]{2}{*}{ Studv or Subgroup } & \multicolumn{3}{|c|}{ DAA } & \multicolumn{2}{|c|}{ PLA } & \multirow[b]{2}{*}{ Total } & \multirow[b]{2}{*}{ Weight } & \multirow{2}{*}{$\begin{array}{l}\text { Mean Difference } \\
\text { IV, Random, } 95 \% \mathrm{Cl}\end{array}$} & \multirow{2}{*}{$\begin{array}{l}\text { Mean Difference } \\
\text { IV, Random, } 95 \% \mathrm{Cl}\end{array}$} \\
\hline & Mean & SD & Total & Mean & SD & & & & \\
\hline Anne J Spaans 2012 & 49 & 8 & 46 & 46 & 5.8 & 46 & $12.0 \%$ & $3.00[0.14,5.86]$ & $=$ \\
\hline Bas Fransen 2016 & 42.7 & 5 & 45 & 45.8 & 4.5 & 38 & $14.0 \%$ & $-3.10[-5.14,-1.06]$ & $\longrightarrow$ \\
\hline Denis nam 2013 & 39.2 & 6.6 & 110 & 44.1 & 5.1 & 110 & $15.1 \%$ & $-4.90[-6.46,-3.34]$ & - \\
\hline Fei Hu 2020 & 41.17 & 3.38 & 110 & 41.37 & 3.25 & 98 & $16.3 \%$ & $-0.20[-1.10,0.70]$ & \\
\hline Hai-Yan Zhao 2017 & 40.3 & 2.8 & 60 & 41.8 & 3.4 & 60 & $16.0 \%$ & $-1.50[-2.61,-0.39]$ & $=$ \\
\hline Han Wu 2020 & 40 & 3.45 & 24 & 41.21 & 2.85 & 23 & $14.6 \%$ & $-1.21[-3.02,0.60]$ & \\
\hline William P.Barrett 2013 & 47.1 & 6.1 & 43 & 42.4 & 7.6 & 44 & $11.9 \%$ & $4.70[1.81,7.59]$ & $\longrightarrow$ \\
\hline \multirow{2}{*}{\multicolumn{8}{|c|}{$\begin{array}{l}\text { Total }(95 \% \mathrm{Cl}) \\
\text { Heterogeneity: } \mathrm{Tau}^{2}=5.10 ; \mathrm{Chi}^{2}=54.20, \mathrm{di8}=6(\mathrm{P}=0.00001) ; \mathrm{I}^{2}=89 \% \\
\text { Test for overall effect: } Z=0.76(\mathrm{P}=0.45)\end{array}$}} & $-0.70[-2.53,1.12]$ & \\
\hline & & & & & & & & & $\begin{array}{ccccc}1 & 1 & 1 & 1 & 1 \\
-10 & -5 & 0 & 5 & 10 \\
\text { Favours [DAA] } & \text { Favours [PLA] }\end{array}$ \\
\hline \multicolumn{9}{|c|}{ Fig. 18 Forest plot comparing the abduction angle of DAA and PLA } & \\
\hline
\end{tabular}

\section{HOOS}

Hip disability and osteoarthritis outcome (HOOS) [20, 21, $23,26,33]$ was divided into two subgroups: mental composite scale and physical composite scale. Five studies (481 participants) were included. The results obtained can prove that the difference was no statistically significant (WMD = $1.99,95 \%$ CI -0.47 to $4.45, P=0.11$, Fig. 21 ).

\section{Discussion}

\section{Main findings}

The results of our meta-analysis were sufficient to prove that, compared with PLA surgery, DAA had a shorter length of hospital stay and LLD, less PE/DVT and dislocation, faster and earlier recovery of hip function; however, DAA also had longer operative time and more intraoperative blood loss and fracture. There was no statistically significant difference between two groups in the aspects of incision length, pneumonia, infection, hematoma rate, re-operation. Postoperative imaging evaluation indicated that there was no statistically significant difference in abduction and anteversion angle.

\section{Comparison with previously published meta-analyses}

There are many differences between us and the previously published meta-analysis. The article of Jia et al. [28] was an analysis of the PA, which includes the PLA.

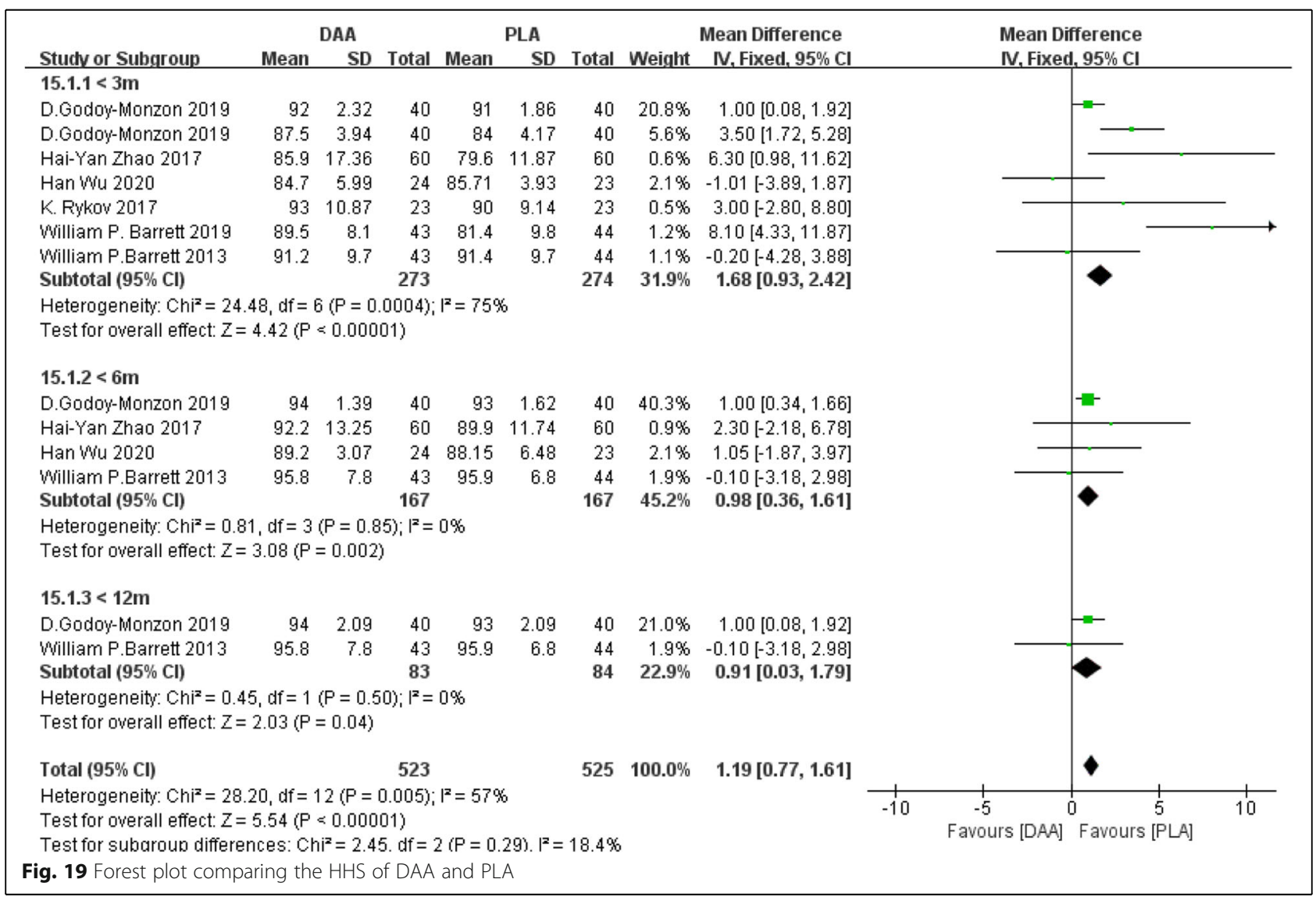




\begin{tabular}{|c|c|c|c|c|c|c|c|c|c|c|}
\hline \multirow[b]{2}{*}{ Studv or Subgroup } & \multicolumn{3}{|c|}{ Experimental } & \multicolumn{2}{|c|}{ Control } & \multirow[b]{2}{*}{ Total } & \multirow[b]{2}{*}{ Weight } & \multirow{2}{*}{$\begin{array}{l}\text { Mean Difference } \\
\text { IV, Random, } 95 \% \mathrm{Cl}\end{array}$} & \multirow{2}{*}{\multicolumn{2}{|c|}{$\begin{array}{l}\text { Mean Difference } \\
\text { IV, Random, } 95 \% \mathrm{Cl}\end{array}$}} \\
\hline & Mean & SD & Total & Mean & SD & & & & & \\
\hline \multicolumn{11}{|c|}{ 16.1.1 VAS $24 \mathrm{~h}$ postoperation } \\
\hline Hai-Yan Zhao 2017 & 3.07 & 0.84 & 60 & 3.79 & 0.96 & 60 & $22.8 \%$ & $-0.72[-1.04,-0.40]$ & $\rightarrow$ & \\
\hline Jetse Jelsma 2016 & 1.67 & 1.85 & 87 & 1.6 & 1.81 & 32 & $12.1 \%$ & $0.07[-0.67,0.81]$ & . & \\
\hline William P.Barrett 2013 & 4 & 1 & 43 & 4.5 & 1.2 & 44 & $18.7 \%$ & $-0.50[-0.96,-0.04]$ & & \\
\hline Subtotal $(95 \% \mathrm{Cl})$ & & & 190 & & & 136 & $53.7 \%$ & $-0.49[-0.87,-0.11]$ & & \\
\hline \multicolumn{11}{|c|}{$\begin{array}{l}\text { Heterogeneity: } \mathrm{Tau}^{2}=0.05 ; \mathrm{Chi}^{2}=3.81, \mathrm{df}=2(\mathrm{P}=0.15) ; \mathrm{I}^{2}=47 \% \\
\text { Test for overall effect: } Z=2.55(\mathrm{P}=0.01)\end{array}$} \\
\hline \multicolumn{11}{|c|}{ 16.1.2 VAS $48 \mathrm{~h}$ postoperation } \\
\hline Hai-Yan Zhao 2017 & 2.11 & 0.28 & 60 & 3.09 & 0.58 & 60 & $27.0 \%$ & $-0.98[-1.14,-0.82]$ & 불 & \\
\hline William P.Barrett 2013 & 3.8 & 1.1 & 43 & 4.1 & 1 & 44 & $19.3 \%$ & $-0.30[-0.74,0.14]$ & & \\
\hline Subtotal $(95 \% \mathrm{Cl})$ & & & 103 & & & 104 & $46.3 \%$ & $-0.67[-1.34,-0.01]$ & & \\
\hline \multicolumn{11}{|c|}{$\begin{array}{l}\text { Heterogeneity: } \operatorname{Tau}^{2}=0.20 ; \mathrm{Ch}^{2}=8.00, \mathrm{df}=1(\mathrm{P}=0.005) ; \mathrm{I}^{2}=88 \% \\
\text { Test for overall effect: } Z=1.99(\mathrm{P}=0.05)\end{array}$} \\
\hline Total $(95 \% \mathrm{Cl})$ & & & 293 & & & 240 & $100.0 \%$ & $-0.57[-0.91,-0.23]$ & & \\
\hline \multicolumn{9}{|c|}{$\begin{array}{l}\text { Heterogeneity: } \operatorname{Tau}^{2}=0.10 ; \mathrm{Ch}^{2}=16.77, \mathrm{df}=4(\mathrm{P}=0.002) ; \mathrm{I}^{2}=76 \% \\
\text { Test for overall effect: } \mathrm{Z}=3.32(\mathrm{P}=0.0009) \\
\text { Test for subaroun differences: } \mathrm{Ch}^{2}=0.21 . \mathrm{df}=1(\mathrm{P}=0.65) . \mathrm{I}^{2}=0 \%\end{array}$} & $-4 \quad-2$ & Favours [PLA] \\
\hline
\end{tabular}

Since PA was not completely equal to PLA, the result of Jia et al. were different from the result of comparing DAA with PLA alone. Both Jia et al. and our study concluded that DAA had shorter hospital stays and longer operative times, and more fractures. Jia et al. concluded that there was no statistical difference between DAA and PLA in LLD and dislocation, while we believed that DAA had smaller LLD and less dislocation than PLA. Jia et al. focuses on the analysis of radiographic results, while we are more interested in intraoperative and postoperative clinical studies. Wang's [29] analysis of the differences between DAA and lateral approach (LA) were fundamentally different from ours. Wang et al. compared DAA with LA, he believes that DAA is more beneficial than LA in reducing postoperative pain, blood loss, and increasing hip function. Our study found that DAA has more blood loss than PLA, which may be related to the longer operative time of DAA.

\section{Implications for clinical practice}

Studies of Jewett and De Geest have shown that the incidence of complications of DAA surgery in the learning curve of surgeons is higher than that of PLA surgery, while the incidence of complications of DAA surgery after the learning curve of surgeons is lower than that of PLA surgery $[41,42]$. In our meta-analysis, we selected literatures that specifically mentioned the surgeon's surgery with high proficiency to discuss the occurrence of six complications. The results of our study prove that although there was no statistically significant difference in

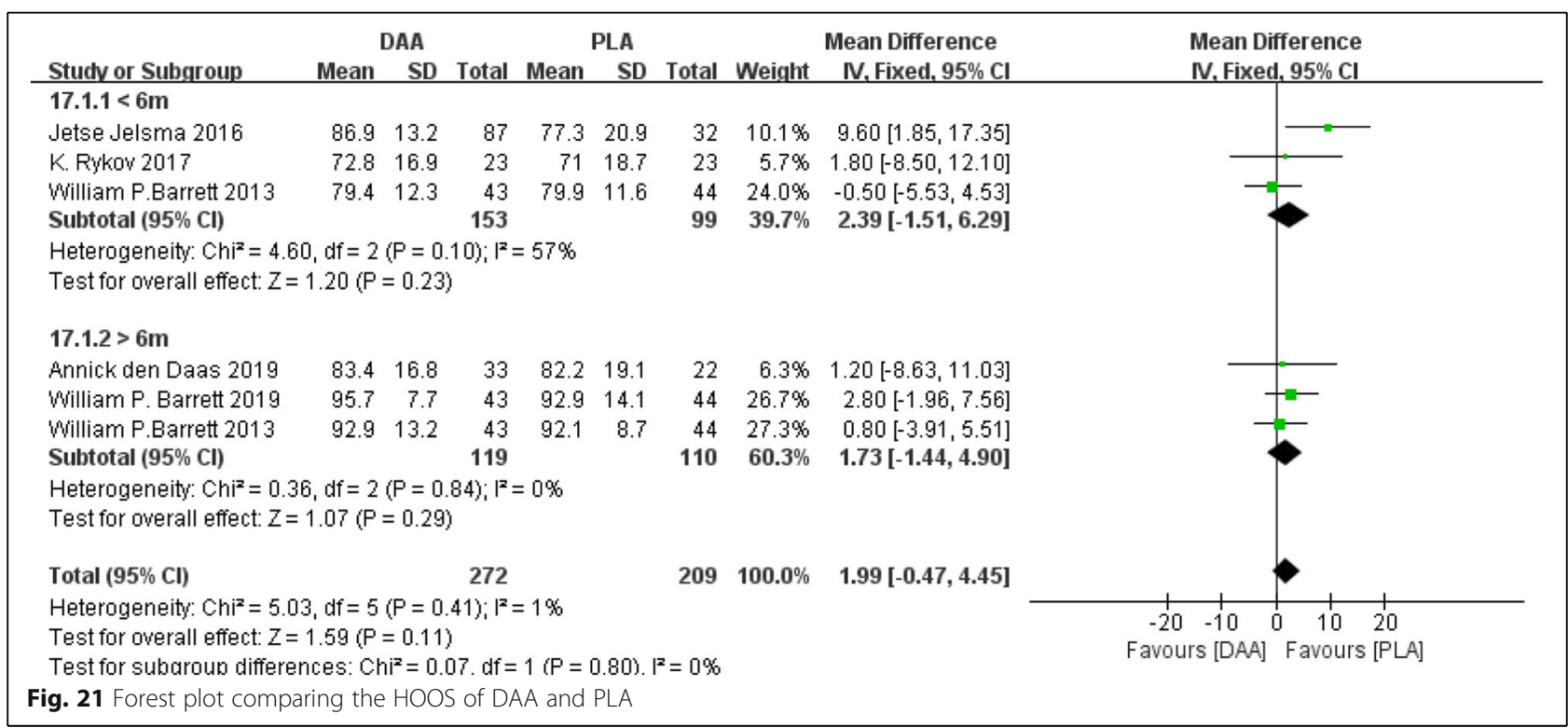


Table 3 Whether the surgeon has passed the learning curve

\begin{tabular}{|c|c|c|c|}
\hline Author & Surgeons proficiency description & Degree of proficiency & Passed learning curve \\
\hline$\overline{\mathrm{Hu}}$ & "performed by a single senior surgeon" & High & Yes \\
\hline Siljander & "had completed more than 100 DA cases" & High & Yes \\
\hline Wu & "easier to achieve femoral exposure than in general hips" & High & ND \\
\hline Barrett & "had performed over 100 DAA cases" & High & Yes \\
\hline Daas & "first half of 2012 and 2011 were excluded, introduced in our hospital in early 2011" & High & Yes \\
\hline Fleischman & "cases performed during a surgeon's learning curve were excluded" & High & Yes \\
\hline Godoy-Monzon & "reducing the possibility of complications attributable to the learning curve" & High & Yes \\
\hline Triantafyllopoulos & "have extensive experience and may be considered experts" & High & Yes \\
\hline Lee & "hip arthroplasty fellowship in both the PLA and the DAA" & High & Yes \\
\hline Rykov & "far beyond the learning curve of the DAA (> 200)" & High & Yes \\
\hline Zhao & "the first 100 patients" "were not enrolled in the current trial" & High & Yes \\
\hline Fransen & "had performed 120 PLA and 80 DAA" & High & Yes \\
\hline Jelsma & "surgeon is using his own approach in which they trust" & High & ND \\
\hline Langlois & "undergoing their subspecialty training" "equivalent to registrars" & High & ND \\
\hline Amlie & "Patients registered before 2011" "were excluded" & High & Yes \\
\hline Barrett & "with over 3000 PA cases vs 100 DAA cases" & High & Yes \\
\hline Nam & "perform more than 200 THAs annually" & High & Yes \\
\hline Spaans & "surgeons had an internal education" "who had used the DAA for 5 years" & High & Yes \\
\hline
\end{tabular}

$\overline{N D}$ unclear description

the three of these complications (pneumonia, infection, hematoma) between the two surgeries, the incidence of PE/DVT, dislocation after DAA was lower than that of PLA surgery. Compared with PLA, DAA has a shorter hospital stay, shorter LLD, less PE/DVT, hip dislocation, and early recovery of joint function. From these perspectives, DAA may be a better surgical method.

\section{Innovation of our meta-analysis}

RCTs and high-quality cohort studies [20-27] were included in our study, and the literatures quality were relatively high. The majority of surgeons in the literature we included passed the learning curve, which made the results more reliable (Table 3). The literatures of inclusion were evaluated strictly, and the possibility of bias is small. The study has a large amount of data and a large number of participants, which is more credible.

\section{Limitations}

Since there was no blind method of participants and personal, most of the literatures has a high risk of bias, so subjective impressions can affect the results. Publication bias exists in this study; however, the degree of bias was acceptable. DAA is a surgical procedure that has only been developed in recent years, so it is not widely used, but it can be learned and mastered. The accuracy of the study may have been affected by the fact that a small number of researchers did not specify in the paper that the surgeon had passed the learning curve, and that the number of patients included in the RCT literatures were less than 50 .

\section{Conclusion}

The study showed that DAA was superior to the PLA after THA in regards to reducing length of hospital stay, LLD, PE/DVT, dislocation. Postoperative pain was mild, and the recovery of hip function was faster and earlier. Thus, DAA may be a better option for patients with hip disease requiring THA. In consideration of the limitations of this study, we need more randomized controlled trials to compare the clinical outcomes of DAA with PLA.

\section{Abbreviations}

DAA: Direct anterior approach; PLA: Posterolateral approach; THA: Total hip arthroplasty; RCT: Randomized controlled trial; WMD: Weighted mean difference; Cl: Confidence interval; OR: Odds ratio; BMI: Body mass index; PRISMA: Preferred Reporting Items for Systematic Reviews and Meta-analyses; VAS: Visual analog scale; HHS: Harris hip score; HOOS: Hip disability and osteoarthritis outcome; PE/DVT: Pulmonary embolism/deep vein thrombosis; LLD: Leg-length difference

\section{Acknowledgements}

None

Authors' contributions

WC, SF, and XYC designed the research ideas, analyzed the data, and wrote out the original manuscript. $Y Z, J N$, and $Y Z$ took part in the design of the study. The co-authors read and authorized the final manuscript for publication. The author(s) read and approved the final manuscript.

Funding

No financial support. 


\section{Availability of data and materials}

All data were contained in the text and charts of published articles.

\section{Ethics approval and consent to participate}

Since all results of this study were based on published research, there was no need for moral endorsement.

\section{Consent for publication}

The co-authors agreed on the final manuscript.

\section{Competing interests}

The co-authors claim there was no competition between them.

\section{Received: 16 April 2020 Accepted: 16 June 2020}

Published online: 23 June 2020

\section{References}

1. Learmonth ID, Young $C$, Rorabeck $C$, et al. The operation of the century: total hip replacement. Lancet. 2007;370(9597):1508-19.

2. Laupacis A, Bourne R, Rorabeck C, et al. The effect of elective total hip replacement on health-related quality of life. J Bone Joint Surg Am. 1993; 75(11):1619-26.

3. (2015) 12th annual report National Joint Registry for England, Wales, Northern Ireland and the Isle of Man.

4. Rachbauer F. Minimally invasive total hip arthroplasty. Anterior approach. Orthopade. 2006:35(7):723-4 726-9.

5. Waddell J, Johnson $\mathrm{K}$, Hein W, et al. Orthopaedic practice in total hip arthroplasty and total knee arthroplasty: results from the Global Orthopaedic Registry (GLORY). Am J Orthop (Belle Mead NJ). 2010;39(9 Suppl):5-13.

6. Bal BS, Vallurupalli $\mathrm{S}$, et al. Minimally invasive total hip arthroplasty with the anterior approach. Indian J Orthop. 2008;42(3):301-8.

7. Kennon RE, Keggi JM, Wetmore RS, et al. Total hip arthroplasty through a minimally invasive anterior surgical approach. J Bone Joint Surg. 2003;85A(Suppl 4):39-48.

8. 12th Annual report 2015. Wales, Northern Ireland and the Isle of Man: National Joint Registry for England; 2015.

9. The New Zealand Joint Registry. Fifteen year report (January 1999 to December 2013). New Zealand: New Zealand Joint Registry; 2014.

10. Bergin PF, Doppelt JD, Kephart CJ, et al. Comparison of minimally invasive direct anterior versus posterior total hip arthroplasty based on inflammation and muscle damage markers. J Bone Joint Surg Am. 2011;93(15):1392-8.

11. Duwelius PJ, Dorr LD, et al. Minimally invasive total hip arthroplasty: an overview of the results. Instr Course Lect. 2008;57:215-22.

12. Berend KR, Lombardi AV Jr, Seng BE, et al. Enhanced early outcomes with the anterior supine intermuscular approach in primary total hip arthroplasty. J Bone Joint Surg Am. 2009;91(Suppl 6):107-20.

13. Smith TO, Blake $V$, Hing CB, et al. Minimally invasive versus conventional exposure for total hip arthroplasty: a systematic review and meta-analysis of clinical and radiological outcomes. Int Orthop. 2011;35(2):173-84.

14. $\mathrm{Xu} \mathrm{CP,} \mathrm{Li} \mathrm{X,} \mathrm{Song} \mathrm{JQ,} \mathrm{et} \mathrm{al.} \mathrm{Mini-incision} \mathrm{versus} \mathrm{standard} \mathrm{incision} \mathrm{total} \mathrm{hip}$ arthroplasty regarding surgical outcomes: a systematic review and metaanalysis of randomized controlled trials. PLoS One. 2013;8(11):e80021.

15. Paillard $P$, et al. Hip replacement by a minimal anterior approach. Int Orthop. 2007:31(Suppl 1):S13-5.

16. Bhandari M, Matta JM, Dodgin D, et al. Outcomes following the singleincision anterior approach to total hip arthroplasty: a multicenter observational study. Orthop Clin North Am. 2009;40(3):329-42.

17. Graves SC, Dropkin BM, Keeney BJ, et al. Does surgical approach affect patientreported function after primary THA? Clin Orthop Relat Res. 2016;474(4):971-81.

18. Lee GC, Marconi D, et al. Complications following direct anterior hip procedures: costs to both patients and surgeons. J Arthroplast. 2015;30(9 Suppl):98-101.

19. De Geest $T$, Fennema $P$, Lenaerts $G$, et al. Adverse effects associated with the direct anterior approach for total hip arthroplasty: a Bayesian metaanalysis. Arch Orthop Trauma Surg. 2015;135(8):1183-92.

20. Barrett WP, Turner SE, Murphy JA, et al. Prospective, randomized study of direct anterior approach vs posterolateral approach total hip arthroplasty: a concise 5-year follow-up evaluation. J Arthroplast. 2019;34(6):1139-42.

21. Rykov K, Reininga IHF, Sietsma MS, Knobben BAS, ten Have BLEF. Posterolateral vs direct anterior approach in total hip arthroplasty (POLADA trial): a randomized controlled trial to assess differences in serum markers. J Arthroplast. 2017:32(12):3652-8.

22. Zhao HY, Kang PD, Xia YY, et al. Comparison of early functional recovery after total hip arthroplasty using a direct anterior or posterolateral approach a randomized controlled trial. J Arthroplast. 2017;32(11):3421-8.

23. Barrett WP, Turner SE, Leopold JP. Prospective randomized study of direct anterior vs postero-lateral approach for total hip arthroplasty. J Arthreplasty. 2013;28(9):1634-8.

24. Hu F, Shang $X$, Zhang $X$, et al. Direct anterior approach in lateral position achieves superior cup orientation in total hip arthroplasty: a radiological comparative study of two consecutive series. Int Orthop. 2020:44(3):453-9.

25. Godoy-Monzon D, Buttaro M, Comba F, et al. Comparative study of radiological and functional outcomes following a direct anterior approach versus to a posterolateral approach to the hip. Rev Esp Cir Ortop Traumatol. 2019:63(5):370-5.

26. Jelsma J, Pijnenburg R. Boons Hw, et al. Limited benefits of the direct anterior approach in primary hip arthroplasty: a prospective single centre cohort study. J Oahop. 2016;14(1):53-8.

27. Langlois J, Delambre J, Klouche S, et al. Direct anterior Hueter approach is a safe and effective approach to perform a bipolar hemiarthroplasty for femoral neck fracture: outcome in 82 patients. Acta Orthop. 2015;86(3):358-62.

28. Jia F, Guo B, Xu F, et al. A comparison of clinical, radiographic and surgical outcomes of total hip arthroplasty between direct anterior and posterior approaches: a systematic review and meta-analysis. HIP International. 2019;29(6):584-96.

29. Wang Z, Bao H, Hou J. Direct anterior versus lateral approaches for clinical outcomes after total hip arthroplasty: a meta-analysis. J Orthop Surg Res. 2019;14(1):63.

30. Moher D, Liberati A, Tetzlaff J, et al. Preferred reporting items for systematic reviews and meta-analyses: the PRISMA statement. J Clin Epidemiol. 2009; 10:1006-12.

31. Siljander MP, Whaley JD, Koueiter DM, et al. Length of stay, discharge disposition, and 90-day complications and revisions following primary total hip arthroplasty: a comparison of the direct anterior, posterolateral, and direct superior approaches. J Arthroplast. 2020;50883-5403(20):30119-4.

32. $\mathrm{Wu} \mathrm{H}$, Cheng WD, Jing J. Total hip arthroplasty by direct anterior approach in the lateral position for the treatment of ankylosed hips. Eur J Orthop Surg Traumatol. 2020

33. den Daas A, Reitsma EA, Knobben BAS, et al. Patient satisfaction in different approaches for total hip arthroplasty. Orthopaedics Traumatology Surgery Research. 2019;105(7):1277-82.

34. Fleischman AN, Tarabichi M, Magner Z, et al. Mechanical complications following total hip arthroplasty based on surgical approach: a large, singleinstitution cohort study. J Arthroplast. 2019;34(6):1255-60.

35. Triantafyllopoulos GK, Memtsoudis SG, Wang H, et al. Surgical approach does not affect deep infection rate after primary total hip arthroplasty. Hip Int. 2019;29(6):597-602.

36. Lee SH, Kang SW, Jo S. Perioperative comparison of hip arthroplasty using the direct anterior approach with the posterolateral approach. Hip Pelvis. 2017;29(4):240-6.

37. Fransen $\mathrm{B}$, Hoozemans M, Vos S. Direct anterior approach versus posterolateral approach in total hip arthroplasty: one surgeon, two approaches. Acta Orthop Belg. 2016;82(2):240-8.

38. Amlie E, Havelin LI, Furnes O, et al. Worse patient-reported outcome after lateral approach than after anterior and posterolateral approach in primary hip arthroplasty. A cross-sectional questionnaire study of 1,476 patients 1-3 years after surgery. Acta Orthop. 2014;85(5):463-9.

39. Nam D, Sculco PK, Abdel MP, et al. Leg-length inequalities following THA based on surgical technique. Orthopedics. 2013;36(4):e395-400.

40. Spaans AJ, van den Hout JA, Bolder SB. High complication rate in the early experience of minimally invasive total hip arthroplasty by the direct anterior approach. Acta Orthop. 2012:83(4):342-6.

41. Jewett BA, Collis DK. High complication rate with anterior total hip arthroplasties on a fracture table[J]. Clin Orthop Relat Res. 2011;469(2):503-7.

42. De Geest T, Vansintjan P, De Loore G. Direct anterior total hip arthroplasty: complications and early outcome in a series of 300 cases. Acta Orthop Belg. 2013:79(2):166-73.

\section{Publisher's Note}

Springer Nature remains neutral with regard to jurisdictional claims in published maps and institutional affiliations. 